\title{
The hardware design and analysis of automatic temperature control and water supply of the boiler
}

\author{
Guang WU ${ }^{1, a}$, Chuanqi DENG ${ }^{2}$, Min $\mathrm{ZHANG}^{3}$, Shuai $\mathrm{CHEN}^{4}$, \\ Jiahui SONG ${ }^{5}$ \\ $1,2,3,4,5$ School of mechanical engineering, Anhui University Of Science and Technology, Huainan, \\ 232001, China \\ aemail: gwu@aust.edu.cn
}

Keywords: STC89C52 MCU; Level Control; Temperature Control; Voice Alarm

\begin{abstract}
This paper focuses on the design and manufacture of automatic temperature control and water supply of the boiler based on STC89C52RC MCU.The system can achieve the functions are: temperature control, liquid level control, voice broadcast and so on . Through the use of single-chip microcomputer to achieve control, easy to realize the boiler level detection, temperature detection and control ,this system has the advantages of low cost, easy debugging, no interference between the various parts of the work, convenient maintenance and so on.
\end{abstract}

\section{Introduction}

In modern society, residents of district heating supply and demand is more and more big, quantity of the domestic coal-fired boiler remains high with the rapid development of industry and improvement of people's living standard[1]. Based on this situation, improve the capacity of steam boiler, strict requirements for the operation and control process are conducive to ease the supply pressure. At the same time, the accurate control of the level and temperature of the boiler is an important issue to the safety of people and equipment. It is difficult to establish the exact mathematical model of the controlled object because of the nonlinear, time-varying, strong coupling and random interference between the controlled object and the process, it is difficult to establish the exact mathematical model of the controlled object[2]. Based on the various influencing factors, the traditional control method can not achieve the required control precision and system stability.

In recent years, automatic control technology development is speeding up with the development and gradual maturity of the single-chip technology, using single-chip microcomputer and its peripheral chips to realize the control of complex systems has become a reality, and also become a development trend of [3]. Boiler's automatic temperature control water supply system is take the advantage of SCM that the boiler system has a high practical value and superiority [4]. The automatic control and adjustment of heating and water supply system is realized by microcomputer, which will ensure the normal supply of water supply to the boiler, maintain the stable system and ensure the safe and economic operation.

\section{System Profile}

The main research object of this design is the temperature and liquid level in the boiler, and the level and temperature of the boiler can realize automatic control. The scheme is as follows:

Through the stc89c52rc MCU, temperature sensor DS18B20, LCM (LCD), voice module (WT588D), float type liquid level sensor, independent key and so on to realize the dual function of temperature, liquid level alarm and control , and also has the boiler current state display, broadcast and control function. The hardware design of the system includes the following modules: stc89c52rc chip as the core control module, level acquisition module, the temperature acquisition module, keyboard module, liquid crystal display module, a voice alarm module, independent key module, a relay control module, power module and the serial interface module.

Specific functions can be achieved as follows: 
(1) play the boot screen and boot music, display the system's default temperature after the start of the system

(2) shows that the current temperature and temperature in the set range, while showing the current status of the liquid level.

(3) When the liquid level is low to a given lower level, the water pump stops the boiler water, and the water pump is started to add water to the boiler, until the liquid level reaches the specified value, and the LCM display liquid level is normal.

(4) When the liquid level is high to a given time limit, the water pump stops to add water to the boiler, and start the water pump to the boiler water, until the liquid level reaches the specified value, LCM display liquid level is normal.

(5) The system stops working when LCM prompts the error when the temperature sensor DS18B20 is damaged.

(6) The heating work is started when the temperature is below the set value and the heating work is stopped when the temperature reaches the specified temperature.

(7) Can voice broadcast, and control voice broadcast on the open and close through the independent button.

(8) Through the button to achieve the upper and lower limits of the temperature setting, the maximum upper limit of 70 degrees Celsius and the minimum threshold value of 10 degrees Celsius.

\section{Hardware Design of the System}

\section{SCM Interface Schematic}

This part is mainly composed of single chip, the pull-up resistor array, etc.. The schematic diagram is shown in Figure 1

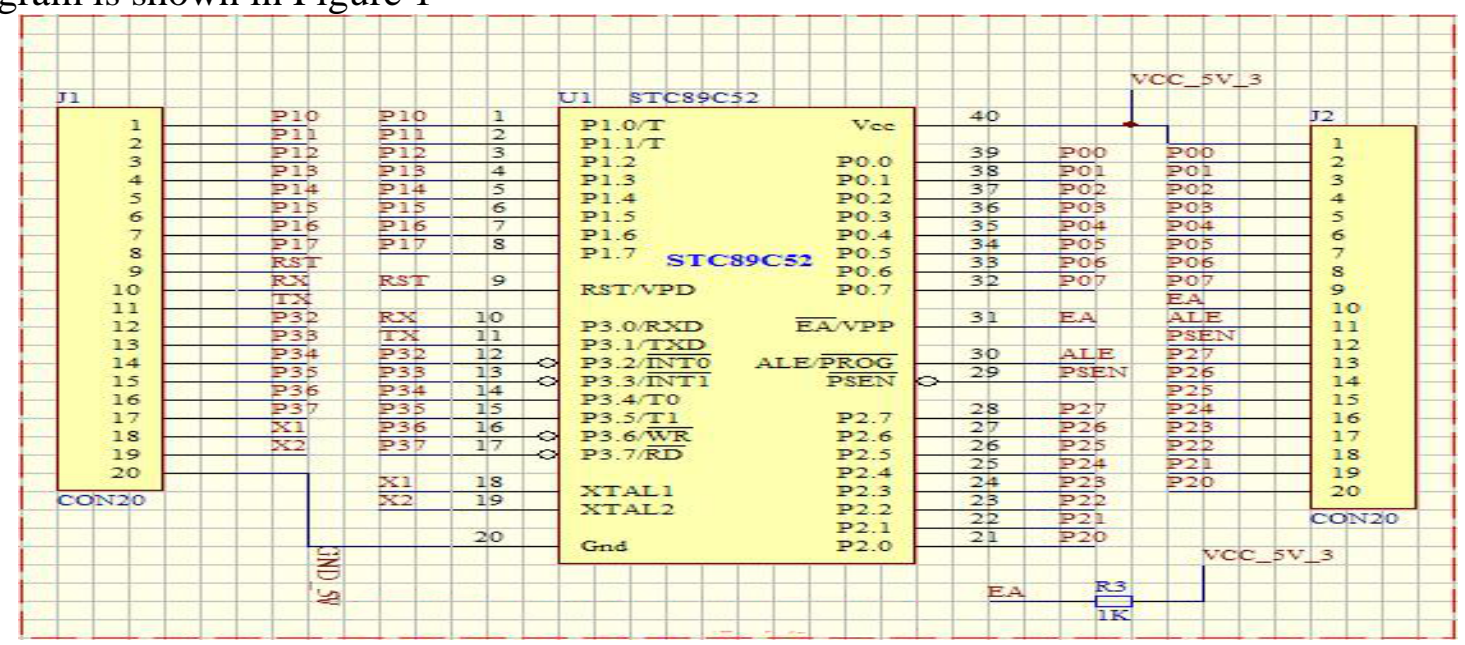

Fig.1. Single chip microcomputer interface circuit

\section{Temperature Acquisition Module}

Temperature acquisition module mainly uses the DS18B20 produced by digital temperature sensor DALLAS semiconductor company. DS18B20 has single wire interface and stable performance. Its hardware interface is simple, only need one port line and MCU connection can realize two-way communication, no need peripheral components. The user can automatically set the upper and lower limit of the temperature alarm, and the value is not easy to lose, at the same time, the alarm search command can identify the DS18B20's ultra temperature limit.

To well solve the problem of lead error compensation multi-point measurement error and amplifyingcircuit switching technologies such as zero drift error problem, can achieve highmeasuring accuracy in the traditional analog signal distance temperature measuring system. In 
general monitoring site, a variety of electromagnetic interference signal is strong, the transmission of analog temperature signal will produce measurement errors, which affect the system measurement, control accuracy. The DS18B20 is suitable for the intelligent temperature measurement and control system, which is easy to be guaranteed. Small size, no need to calibrate, support multi point network function, and can be used to measure temperature and other characteristics are conducive to the practical application to achieve good temperature measurement results. As shown in Figure 2[7]

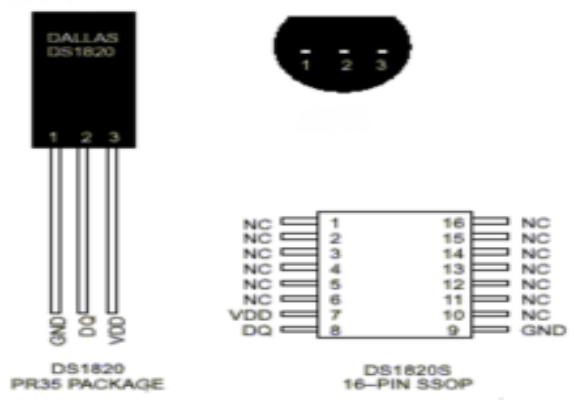

Fig.2. DS18B20 temperature sensor

The schematic diagram of

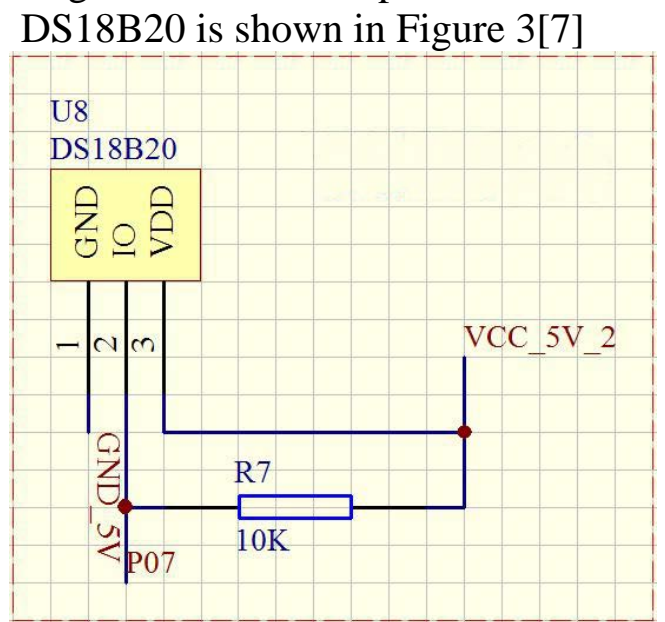

Fig. 3. Schematic diagram of DS18B20

\section{Liquid Level Acquisition Module}

The float type liquid level switch is adopted by the liquid level sensor. The floating ball type liquid level switch is mainly composed of a magnetic reed switch, a floating ball and a junction box. The structure is simple, no complicated circuit, convenient use, no need for power supply of the magnetic spring switch, long service life, and the control switch position can be customized with the user. All the switch outlets are in the same junction box, and the cost of external construction wiring is low. The liquid level switch can be safely used on the high temperature and high pressure equipment because the magnetic reed switch and the conducting wire are completely isolated from the liquid being tested. As long as the material selection is correct, any nature of the liquid or pressure, temperature can be used. Float type liquid level switch is used in direct drive float magnetic reed switch internal magnet, to switch the moment action principle. The floating ball and the magnetic reed switch are controlled by the fixed ring in the closed metal or plastic pipe. When the measured medium is float, the float can move in a certain range, the magnet in floating ball will attract magnet on control switch action bar, resulting in the opening and closing action,and realizing the liquid level indication and control (when the floating ball is close to the magnetic reed switch is 
conduction; left switch is disconnected) [8] .

The kind of liquid level sensor is shown in Figure 4

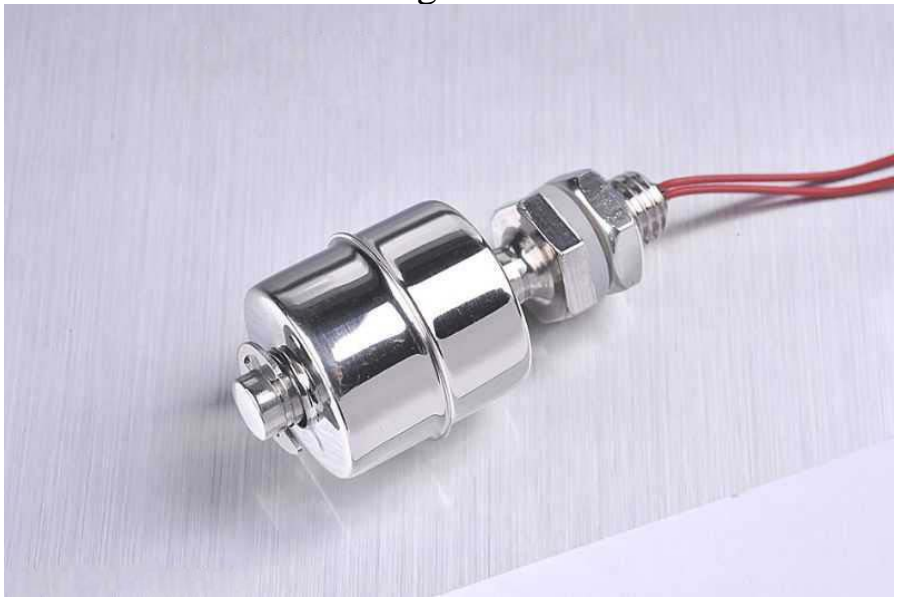

Fig.4. Floating ball type liquid level sensor

The circuit diagram of the liquid level acquisition module is shown in Figure 5

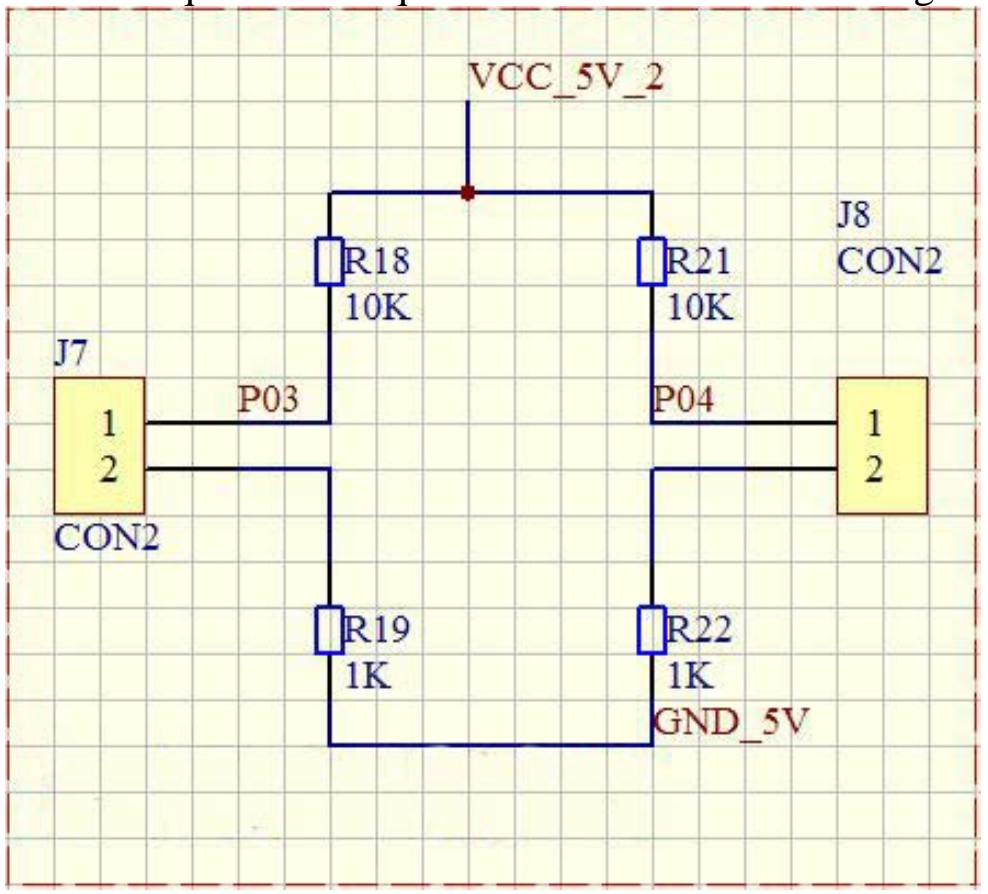

Fig.5. Interface circuit of liquid level sensor

\section{Relay Control Module}

Relay is mainly to do the role of automatic control of the switch components. The design of the Chinese Communist Party used 3 electromagnetic relays, which are using +5V DC power to control the $12 \mathrm{~V}$ DC, respectively, to achieve the water pump, water pump, heater control. Electromagnetic relay circuit can work with low voltage and weak current control circuit to control the high voltage, high current, and can realize remote control and automatic control[9]. Produced by electromagnetic effect to drive the armature actuation of the movable contact and the fixed contact (normally open contacts), release, so as to achieve to be communicated and cut off in the circuit. The control of the water pump, the water outlet water pump and the heater can be automatically controlled by the principle. Relay control circuit as shown in Figure 6[10] 


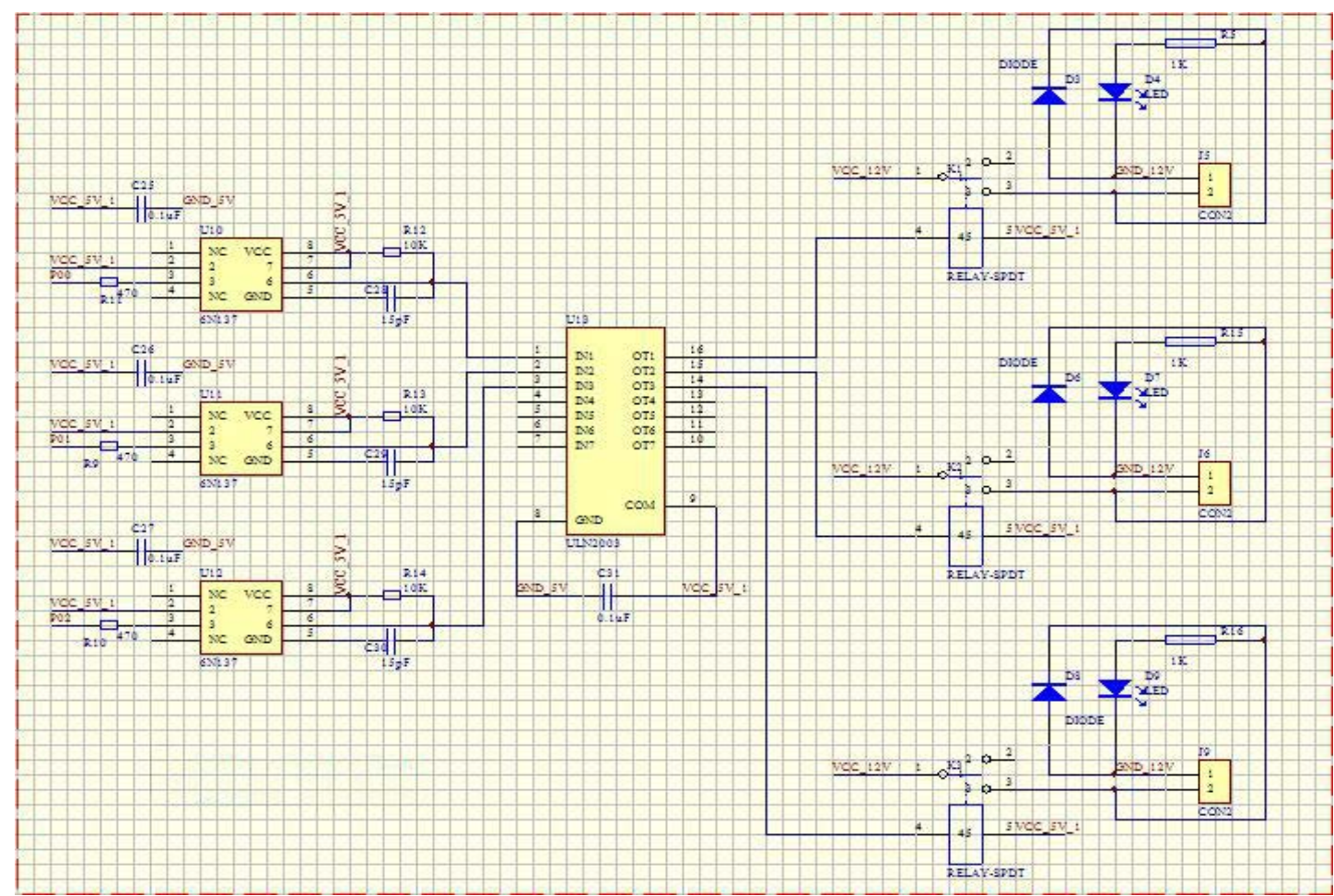

Fig.6. Relay control circuit

\section{Structure Design}
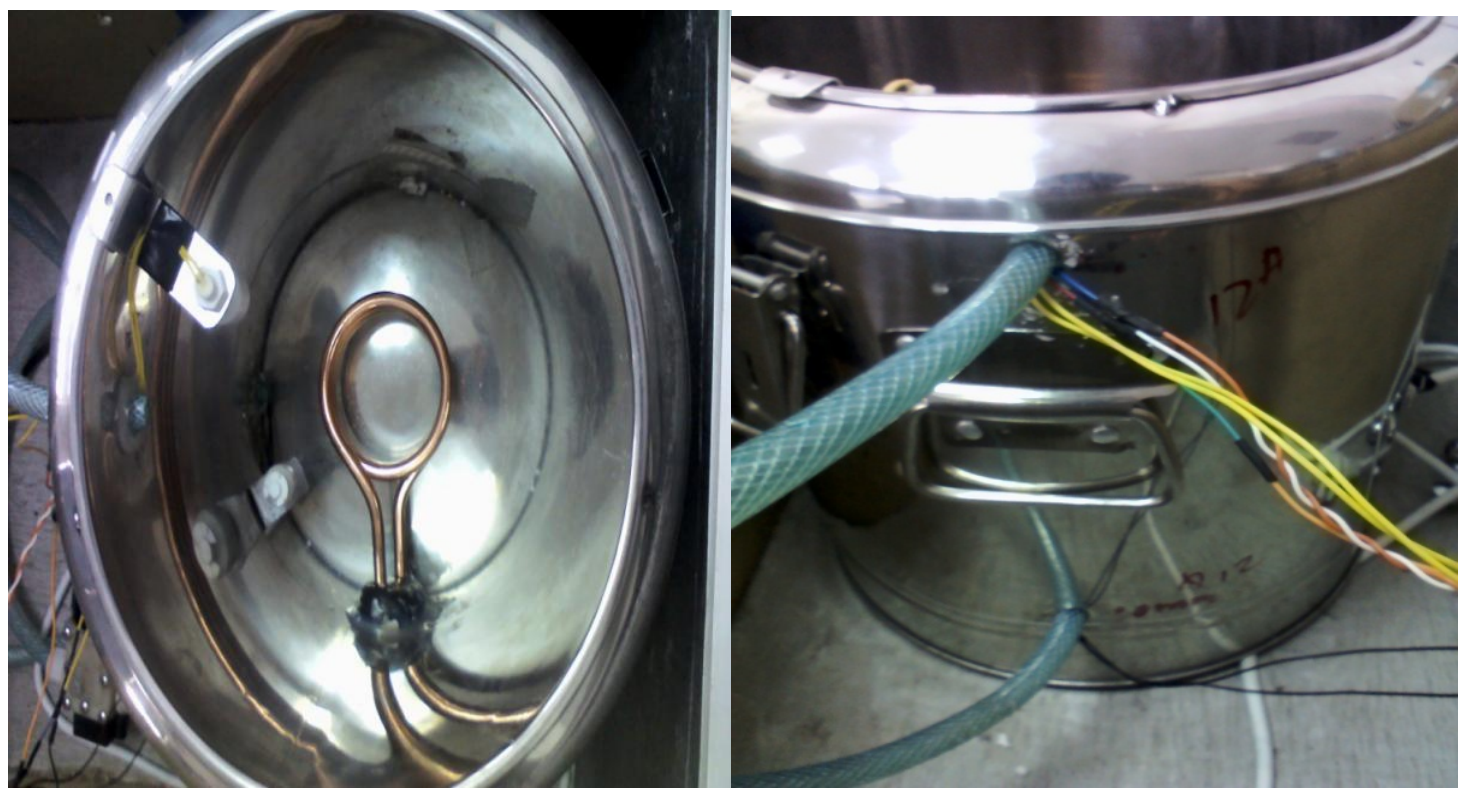

Fig.7. Thermal insulation bucket

Fig.8. The trend of water pipe and signal line

The heat preservation barrel used in the design is based on the finished product to carry out some processing income. Machining including by opening holes on the barrel wall, positioned heater, installation and sealing, import and the positioning of the water pipe, installation and sealing, design and installation of liquid level sensor, and installation of the liquid level sensor and temperature sensor DS18B20, fixed. When the liquid level sensor is installed, the float of the liquid level sensor is flush with the water inlet pipe, when the water level reaches the edge of the float of the liquid level sensor, the water is stopped, and the water inlet pipe is completely submerged. When liquid level sensor is arranged, the lower edge of the floating ball is slightly higher than that of the heating device, and when the liquid level barrel below the liquid level sensor on the edge, stop the water also began to add water, to prevent the liquid level is too low and lead to dry combustion heating device. The processing results are shown in Figure 7. 
The signal lines of the upper and the lower liquid level sensors are respectively drawn out from the holes of the water inlet and outlet pipes of the installation. The DS18B20 temperature sensor is arranged in the inner part of the heat preservation barrel and is close to the inner wall, and the position is in the middle of the bucket, and the signal line of the signal line is drawn from the water inlet hole from the signal line of the upper level sensor. As shown in Figure 8.

\section{Application analysis}

The system controls the relay to make the water pump work when the liquid lever is too low, and the system controls the relay to make the water pump work when the liquid lever is too high, until the liquid level is normal. Relay control heater heating when the temperature of the water is below the set value ,until reaches the set temperature, heater (220V) stop working, these functions are to to achieve, and the whole process is automatically, without any need for user, the user only need to set temperature range according to their own requirements,this work is safe and convenient.

Boiler automatic control water supply system have been verified by experiments, can realize the boot screen display, the default temperature limit values are displayed to the user according to their own needs set. Finally system display the current temperature, liquid level and whether it is normal state.

With the development of single-chip technology and mature , SCM is not only wide application prospect, but also help to find out the possible fault . Boiler automatic temperature control water supply system is the use of SCM, so that the boiler system has a high practical value and superiority.

\section{References}

[1] Qisheng Xu. Boiler equipment and system [M]. Beijing: China Electric Power Press, 2011.

[2] Lei Zhang ,Fei Feng , Zhongqiang Tu. Boiler operation and equipment [M]. Beijing: Chemical Industry Press, 2011.

[3] Yanhua Meng. Safe operation and management of industrial boiler [M]. Beijing: China Electric Power Press, 2004.

[4] Shibai Tong .The basis of analog electronic technology [M] .Beijing: Higher Education Press, 2001.

[5] Mark.N. Horestein. Microelectronic Circuits and Device[P]. New Jersey: Prentice-Hall,1996.

[6] Aubrey Pilgrim. Build Your Own Pentium PC and Save a Bundle[M]. New York : MeGraw-Hill,1989.

[7] Shi Yan. Fundamentals of digital electronic technology [M]. Beijing: Higher Education Press, 1998.

[8] Qinglin Wang. Circuit design and production: 99SE Protel basic tutorial [M]. Beijing: People's Posts and Telecommunications Press, 2012.

[9] Li Wang, Wei Zhang . Circuit design and production: 99SE Protel typical example [M]. Beijing: People's Posts and Telecommunications Press, 2006.

[10] Jingxia Wang. Application technology of single chip microcomputer [M]. Beijing: Publishing House of electronics industry (C language version), 2009. 